\title{
BMJ Open Effect of physical exercise on weight loss and physical function following bariatric surgery: a meta-analysis of randomised controlled trials
}

\author{
Zi-Qi Ren, ${ }^{1}$ Guang-Dong Lu, ${ }^{2}$ Tian-Zi Zhang, ${ }^{1}$ Qin Xu ${ }^{1}$
}

To cite: Ren Z-Q, Lu G-D, Zhang T-Z, et al. Effect of physical exercise on weight loss and physical function following bariatric surgery: a meta-analysis of randomised controlled trials. BMJ Open 2018;8:e023208. doi:10.1136/ bmjopen-2018-023208

- Prepublication history and additional material for this paper are available online. To view these files, please visit the journal online (http://dx.doi. org/10.1136/bmjopen-2018023208).

Received 29 March 2018 Revised 10 August 2018 Accepted 3 October 2018
Check for updates

(C) Author(s) (or their employer(s)) 2018. Re-use permitted under CC BY-NC. No commercial re-use. See rights and permissions. Published by BMJ.

${ }^{1}$ School of Nursing, Nanjing Medical University, Nanjing,

China

${ }^{2}$ Department of Interventional Radiology, the First Affiliated Hospital of Nanjing Medical University, Nanjing, China

Correspondence to

Professor Qin Xu;

qinxu@njmu.edu.cn

\section{ABSTRACT}

Objectives We performed a meta-analysis of all of the available randomised controlled trials (RCTs) to investigate whether physical exercise contributes to weight loss or physical function improvement in adults receiving bariatric surgery.

Methods We searched PubMed, Embase, the Cochrane Library, OVID and the CINAHL up through May 2018. RCTs that assigned adults with obesity to either an exercise training group or a no-exercise group after bariatric surgery were included. The primary outcomes were weight loss and physical function. Study bias was assessed using the Cochrane risk of bias tool, and the quality of evidence was assessed using GRADEpro.

Results A total of eight studies met the inclusion criteria ( $n=347$ participants). Most of the studies carried a low risk of bias due to randomisation and blinding. Compared with those without exercise intervention after surgery, patients engaging in physical exercise were associated with greater weight loss (weighted mean difference (WMD) $-1.94 \mathrm{~kg} ; 95 \% \mathrm{Cl}-3.18$ to $-0.69 ; \mathrm{n}=8$ ) and longer $6 \mathrm{~min}$ walk distance (6MWD; WMD29.67 m; $95 \% \mathrm{Cl} 25.97$ to $33.37 ; n=2$ ) during follow-up. By subgroup analyses, the additional weight loss in exercise group was related to the starting time and type of exercise: patients engaging in exercise 1 year or more after surgery and patients received aerobic-resistance exercise experienced more weight loss Besides, patients in exercise training group also had lower systolic blood pressure and resting heart rate after surgery. The quality of evidence for these outcomes was moderate to very low.

Conclusions Physical exercise after bariatric surgery provides $1.94 \mathrm{~kg}$ additional weight loss and $29.67 \mathrm{~m}$ longer $6 \mathrm{MWD}$ compared with surgery alone. Moreover, engaging in exercise 1 year or more after surgery, and a combined aerobic and resistance training programme may result in greater weight loss.

\section{INTRODUCTION}

Among the multioptional treatments for obesity, bariatric surgery is the most effective one with profound weight loss and a potential increase in functional capacities. ${ }^{12}$ However, not all of the patients achieve desired clinical outcomes, even when surgery is successful. ${ }^{34}$

\section{Strengths and limitations of this study}

This is the first meta-analysis of randomised controlled trials (RCTs) to examine the effect of physical exercise on patients who have had bariatric surgery.

- The power of synthetic outcomes from RCTs was confined by the small sample size and the limited number of included studies.

- The heterogeneity of exercise training interventions also presents challenges to evidence synthesis.

Apart from the effects of different types of bariatric procedures, patients' behavioural changes, such as engaging in physical exercise, also have a marked influence on postsurgery outcomes. ${ }^{5}$

Physical exercise is an important component of lifestyle interventions for weight loss. ${ }^{6}$ Studies of non-surgical weight loss have confirmed that physical exercise helps improve functional capacities and reduce the risk of metabolic diseases through numerous mechanisms, such as decreasing body weight, total body fat and visceral fat. ${ }^{3}$-9 Although physical exercise administered alone does not cause substantial weight reduction, it preserves fat-free mass (FFM) during weight reduction, which may bring about a more favourable outcome in terms of body composition. ${ }^{1011}$ It is logical to believe that these benefits are equally applicable to patients who receive exercise training after bariatric surgery. Earlier systematic review based solely on observational studies suggests that increased participation in physical activity after bariatric surgery is associated with increased weight loss and health quality of life ${ }^{12} 13$; however, several randomised controlled trials (RCTs) obtained inconsistent conclusions.

We therefore conducted a meta-analysis of all of the available RCTs to investigate the effects of physical exercise in patients after 
bariatric surgery. Our study aimed to determine whether engaging in exercise after surgery can provide additional weight loss and improvement in physical function. We hope to find suitable exercise prescriptions that can optimise postoperative outcomes to provide specific guidelines for exercise management in patients undergoing bariatric surgery.

\section{METHODS}

\section{Patient and public involvement}

As it was a meta-analysis, neither patients nor the public were involved in the present study.

\section{Search strategy}

We performed a comprehensive literature search according to PRISMA (Preferred Reporting Items for Systematic Reviews and Meta-Analyses) guidelines ${ }^{14}$ without language restrictions, using PubMed, Embase, the Cochrane Library, OVID and the CINAHL (Cumulative Index of Nursing and Allied Health Literature), from inception of each database to May 2018, to identify all of the published RCTs on the effects of physical exercise in patients after bariatric surgery. Search terms included mesh headings and keywords based on bariatric surgery (eg, bariatric surgery OR gastric bypass OR gastric sleeve OR gastric banding OR gastrectomy) and exercise (eg, exercise OR physical exercise OR physical activity OR physical training OR aerobic training OR resistance training) and were modified for each individual database. We also searched the reference lists of the retrieved articles and relevant review articles for further eligible studies. A full electronic search strategy for all of the databases is provided in the online supplementary tables $1-5$.

\section{Eligibility criteria}

Prespecified inclusion criteria were as follows: (1) All of the published RCTs on physical exercise in patients after bariatric surgery were considered for inclusion; (2) Subjects were adults with obesity (age $\geq 18$ years) who had undergone bariatric surgery (all types); (3) For the intervention group(s), modes of exercise regimens were defined as aerobic exercise, resistance training or a combination of both. The control group received only standard care (eg, advice to increase physical activity and healthy eating) or no exercise training; (4) At a minimum, the studies must have assessed weight loss or physical function as an outcome and must have reported mean values or the differences between the mean values. The exclusion criteria were as follows: (1) intervention studies comparing only two kinds of exercise prescriptions without control groups and (2) duplicate publications of the included trials.

\section{Study selection}

Two investigators who were blind to the authors and the journal titles independently evaluated the titles and abstracts of the retrieved articles. Disagreements between the two authors were resolved by discussion with another senior author until consensus was reached. The full-text versions of potentially eligible articles were retrieved for further evaluation.

\section{Data extraction}

Two researchers independently performed data extraction from eligible trials using standardised forms. The following relevant information was recorded: demographic information, methodology, intervention details and all of the reported patient-important outcomes. Disagreements were resolved by discussion with another researcher. When data were missing, authors were contacted to obtain any missing information.

\section{Assessment of risk of bias in included studies}

Included studies were evaluated for methodological quality using the Cochrane Collaboration's tool. ${ }^{15}$ Risk of bias ranged from low to high or was unclear, and individual bias items were assessed as described in Higgins $\mathrm{P}$ and Green S, eds. The Cochrane Handbook for Systematic Reviews of Interventions 5.1.0 (Hoboken, New Jersey, USA: John Wiley \& Sons, 2008), particularly focusing on random-sequence generation, allocation concealment, blinding, outcome assessment and selective reporting. ${ }^{16}$ Two investigators assessed the risk of bias in each included study independently, and disagreements were resolved by consensus.

\section{Outcome justification and measurements}

We chose the outcomes in the present meta-analysis according to previous studies and reviews. ${ }^{17-20}$ The primary outcomes were weight loss (defined as actual weight loss sustained after intervention, in kilograms) and physical function (analysed by results of the $6 \mathrm{~min}$ walk test $(6 \mathrm{MWT}))$. Change in body weight is the most commonly used anthropometric parameter to evaluate the effects of bariatric surgery. ${ }^{21}{ }^{22}$ And 6MWT have been used to quantify functional capacity in obese patients and to monitor changes in physical function after bariatric surgery. ${ }^{23}$ Considering weight loss and physical function accurately reflect the effect of bariatric surgery, so we chose them as primary outcomes. Secondary outcomes were body mass index (BMI, in kilogram per square metre), percentage of total body fat (BF\%), fat mass (FM, in kilogram) and FFM (kilogram), waist circumference and hip circumference (both in centimetre), systolic and diastolic blood pressure (SBP and DBP, respectively, in $\mathrm{mm} \mathrm{Hg}$ (millimetre of mercury)) and heart rate (HR; WMD in beats per minute $(\mathrm{bpm}))$. The definitions of secondary outcomes were not set in advance and we tried our best to synthesise all of the results of included studies as much as possible.

\section{Data synthesis and statistical analysis}

All of the statistical analyses were performed using Stata software V.14. WMDs and associated 95\% CIs were calculated for continuous data. Missing SDs were derived from other statistics. In cases where only the final and baseline 
values were available, we calculated the mean change of the score by subtracting the mean final value from the mean baseline value and computed the change-frombaseline SD using a correlation coefficient. ${ }^{16}$ We used the Cochran's $Q$ test to assess heterogeneity between studies. We also did $\mathrm{I}^{2}$ testing to assess the magnitude of the heterogeneity between studies, regarding values greater than $50 \%$ as indicative of moderate-to-high heterogeneity. ${ }^{25}$ The study weights were assigned via the inverse-variance method, and all calculations were performed using a random-effects model. A p-value $<0.05$ was considered to be statistically significant. Considering the clinical heterogeneity, we carried out subgroup analyses on primary outcomes based on the starting time of the intervention after surgery (within half a year vs 1 year or more vs varying starting times) and types of exercise (aerobic vs resistance vs aerobic-resistance). A formal subgroup test was then used to see if the difference between subgroups is significant or not. ${ }^{26}$ To test the robustness of the pooled results, we performed a sensitivity analysis of primary outcomes by removing each study one by one.

We assessed the possibility of publication bias by constructing a funnel plot of each trial's effect size against the SE. We used funnel plots and the Egger's regression test (for the endpoint of weight loss only) to assess publication bias, ${ }^{27}$ and significant publication bias was defined as a $\mathrm{p}$ value $<0.1$.

\section{Assessment of quality of evidence for each outcome}

We used the GRADEpro Guideline Development Tool (http://ims.cochrane.org/revman/gradepro, version
3.6) to assess the quality of evidence for each outcome across studies and to generate 'Summary of findings' tables for the comparisons. Using this system, RCTs start out as high-level evidence, however, downgrading randomised trial evidence to moderate, low or even very low quality evidence, depending on the presence of the five factors: risk of bias, inconsistency, indirectness, imprecision and publication bias according to the Cochrane Handbook Systematic Reviews. ${ }^{16}$ Our justifications for judgement in each of these domains as footnotes were reported in the 'Summary of findings' tables.

\section{RESULTS}

\section{Study selection and characteristics}

A total of 1187 potentially eligible records were identified in the preliminary examination. During the selection process, 317 records were eliminated due to duplication, and 835 were excluded based on title and abstract. Of the 35 remaining articles whose full texts we reviewed, 4 were not RCTs, 3 compared two exercise regimens simultaneously, 4 did not provide the required outcomes, 3 were secondary analyses of the original studies and 13 were conference abstracts. Ultimately, we included eight RCTs $^{1728-34}$ in our meta-analysis. The flow chart illustrating the search for and selection of studies is shown in figure 1 .

The eight included trials ${ }^{17} 28-34$ were published from 2011 to 2018 and performed in the USA, ${ }^{28} 30-33$ England, ${ }^{29} \operatorname{Iran}^{17}$ and Denmark. ${ }^{34}$ All of the studies

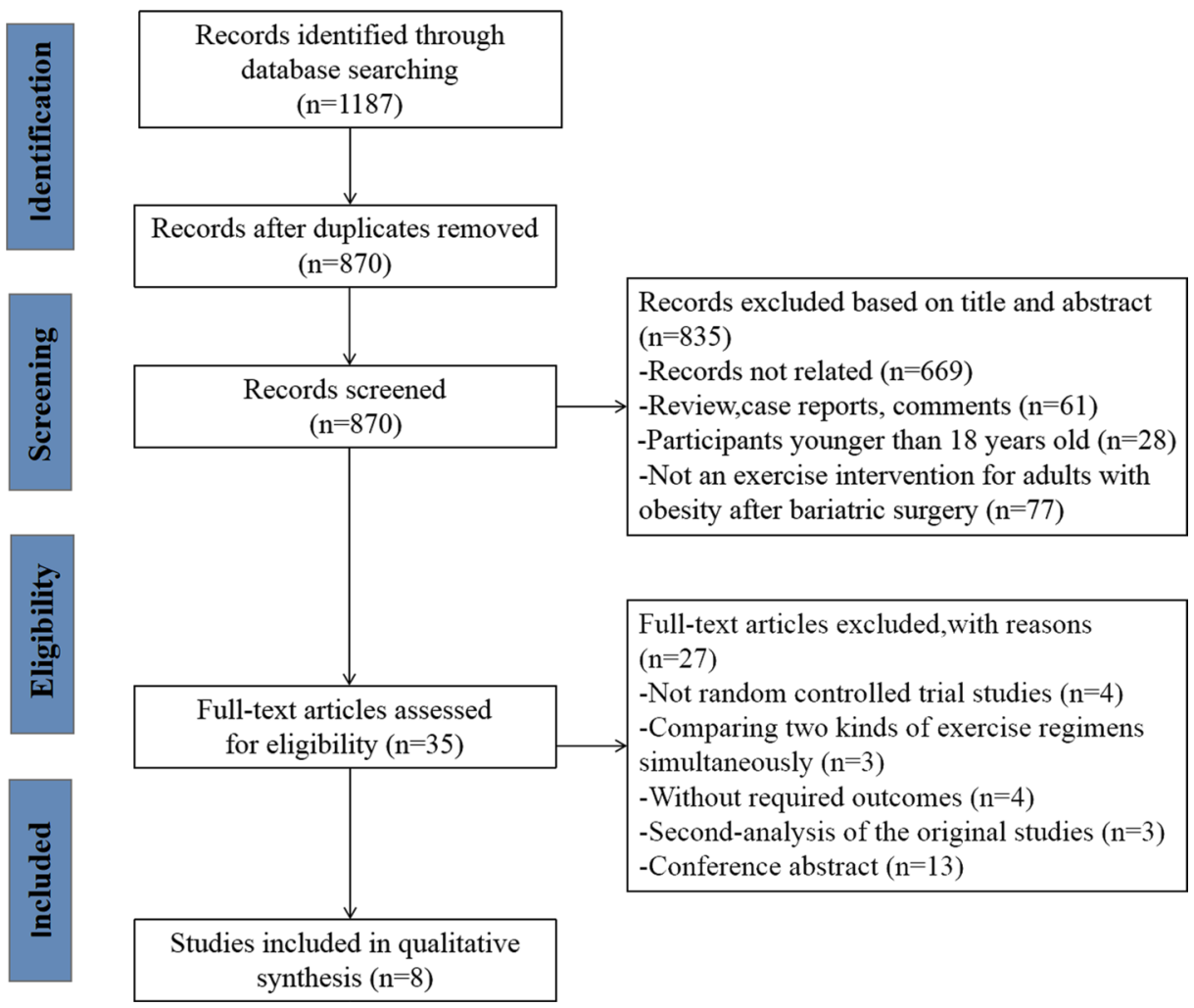

Figure 1 Study selection flow chart. 
Table 1 Characteristics of included studies

\begin{tabular}{|c|c|c|c|c|c|c|c|}
\hline Authors (year) & $\begin{array}{l}\text { No. of } \\
\text { patients }\end{array}$ & $\begin{array}{l}\text { Type of } \\
\text { surgery }\end{array}$ & $\begin{array}{l}\text { Age, mean } \\
\text { (SD), years }\end{array}$ & $\begin{array}{l}\text { Mean time since } \\
\text { surgery }\end{array}$ & $\begin{array}{l}\text { Type of exercise } \\
\text { intervention }\end{array}$ & Exercise regimen & Main outcomes \\
\hline $\begin{array}{l}\text { Castello et } a l^{30} \\
(2011)\end{array}$ & 32 & RYGB & $\begin{array}{l}E: 38(13.3) \\
C: 36(12.6)\end{array}$ & 1 month & Aerobic exercise & $\begin{array}{l}60 \mathrm{~min} / \mathrm{d} * 3 \mathrm{~d} / \mathrm{w} \text { * } \\
12 \mathrm{w}\end{array}$ & $\begin{array}{l}\text { Anthropometric variables } \\
\text { and body composition } \\
\text { 6MWT } \\
\text { HR variability } \\
\text { Spirometric measurements }\end{array}$ \\
\hline $\begin{array}{l}\text { Shah et } a l^{32} \\
(2011)\end{array}$ & 33 & $\begin{array}{l}\text { RYGB } \\
\text { GB }\end{array}$ & $\begin{array}{l}E: 47.3(10) \\
\text { C: } 53.9(8.8)\end{array}$ & $\geq 1$ year & $\begin{array}{l}\text { Moderate-intensity } \\
\text { aerobic exercise }\end{array}$ & $\geq 2000 \mathrm{kcal} / \mathrm{w}$ * $12 \mathrm{w}$ & $\begin{array}{l}\text { Weight loss } \\
\mathrm{VO}_{2 \max } \text { REE } \\
\text { Blood pressure } \\
\text { Health-related QOL }\end{array}$ \\
\hline $\begin{array}{l}\text { Coen et } a l^{28} \\
(2015)\end{array}$ & 128 & RYGB & $\begin{array}{l}E: 41.3(9.7) \\
\text { C: } 47.9(10.3)\end{array}$ & $1-3$ months & $\begin{array}{l}\text { Aerobic exercise } \\
\text { training }\end{array}$ & $\begin{array}{l}\text { 1-3 M: } 10-15 \mathrm{~min} / \mathrm{d} \\
\text { * } 3-5 \mathrm{w} \\
3-6 \mathrm{M}: 30 \mathrm{~min} / \mathrm{d} \\
120 \mathrm{~min} / \mathrm{w}\end{array}$ & $\begin{array}{l}\text { Insulin sensitivity } \\
\text { Cardiorespiratory fitness: } \\
\text { VO } \\
\text { Weight, body composition }\end{array}$ \\
\hline $\begin{array}{l}\text { Coleman et } a l^{31} \\
(2016)\end{array}$ & 51 & $\begin{array}{l}\text { SG } \\
\text { LB } \\
\text { RYGB }\end{array}$ & $49.8(11.4)$ & 14 months & $\begin{array}{l}\text { Strength, flexibility } \\
\text { and aerobic } \\
\text { activities }\end{array}$ & $\begin{array}{l}60 \mathrm{~min} / \mathrm{d} * 2 \mathrm{~d} / \mathrm{w} * 6 \mathrm{M} \\
\text { exercise classes }+ \\
\geq 3 \mathrm{~d} / \mathrm{w} \text { self-directed } \\
\text { exercise * } 6 \mathrm{M}\end{array}$ & $\begin{array}{l}\text { Physical fitness: } 6 \text { min walk } \\
\text { Self-reported physical } \\
\text { activity }\end{array}$ \\
\hline $\begin{array}{l}\text { Hassannejad et al }{ }^{17} \\
(2017)\end{array}$ & 60 & $\begin{array}{l}\text { RYGB } \\
\text { SG }\end{array}$ & $\begin{array}{l}E: 35.4(8.1) \\
\text { C: } 36.7(6.2)\end{array}$ & Immediately after & $\begin{array}{l}\text { Aerobic strength } \\
\text { training }\end{array}$ & $\begin{array}{l}1-4 \mathrm{w} \text { : } \\
\text { walking } \geq 150 \mathrm{~min} / \mathrm{w} \\
5-12 \mathrm{w} \text { : } \\
\text { walking } \geq 150 \mathrm{~min} / \mathrm{w} \\
+ \text { strength exercise } \\
20-30 \mathrm{~min} / \mathrm{d}^{*} 3 \times / \mathrm{w}\end{array}$ & $\begin{array}{l}\text { Anthropometric } \\
\text { measurements } \\
\text { Functional capacity: } \\
\text { 12MWRT, } \\
\text { 1RM, sit-to-stand test }\end{array}$ \\
\hline $\begin{array}{l}\text { Herring et } a l^{29} \\
(2017)\end{array}$ & 24 & $\begin{array}{l}\text { RYGB } \\
\text { SG } \\
\text { GB }\end{array}$ & $48.4(8.9)$ & 19.3 months & $\begin{array}{l}\text { Moderate-intensity } \\
\text { aerobic and } \\
\text { resistance training }\end{array}$ & $\begin{array}{l}60 \text { min gym sessions } \\
{ }^{*} 3 \times / w^{*} 12 w\end{array}$ & $\begin{array}{l}\text { Physical function: ISWT, grip } \\
\text { strength } \\
\text { Anthropometric } \\
\text { measurements } \\
\text { Objective and self-reported } \\
\text { physical activity }\end{array}$ \\
\hline $\begin{array}{l}\text { Daniels et } a l^{33} \\
(2018)\end{array}$ & 16 & RYGB & $44.9(10.2)$ & 8 weeks & Resistance training & $\begin{array}{l}1 \mathrm{w}: 60-80 \mathrm{~min} \\
\text { training }{ }^{*} 3 \times / \mathrm{w} \\
\text { (intensity: } 50 \%-60 \% \\
1 \mathrm{RM}) \\
2-7 \mathrm{w}: 60-80 \mathrm{~min} \\
{ }^{\star} 3 \times / \mathrm{w} \\
\text { (intensity: } 70 \%-80 \% \\
1 \mathrm{RM} \text { ) } \\
8-12 \mathrm{w}: 60-80 \mathrm{~min} \\
{ }^{*} 3 \times / \mathrm{w} \\
\text { (intensity: }>80 \% \\
1 \text { RM) }\end{array}$ & $\begin{array}{l}\text { Body composition } \\
\text { Muscle quality and strength } \\
\text { Muscle cross-sectional area }\end{array}$ \\
\hline $\begin{array}{l}\text { Mundbjerg et } a l^{34} \\
(2018)\end{array}$ & 60 & RYGB & $\begin{array}{l}\text { E: } 42.3(9.4) \\
\text { C: } 42.4(9.0)\end{array}$ & 6 months & $\begin{array}{l}\text { Aerobic and } \\
\text { resistance training }\end{array}$ & $\begin{array}{l}40 \text { min supervised } \\
\text { physical training } \\
\text { sessions }{ }^{*} 2 / w^{*} 26 w\end{array}$ & $\begin{array}{l}\text { Anthropometric variables } \\
\text { Cardiovascular risk factors }\end{array}$ \\
\hline
\end{tabular}

1RM, one repetition maximum; 6MWT, 6 min walk test; 12MWT, 12 min walk test; d, day(s); GB, gastric banding; HR, heart rate; ISWT, incremental shuttle walk test; LB, lap band; M, months; QOL, quality of life; REE, resting energy expenditure; RYGB, roux en-y gastric bypass; $S G$, sleeve gastric; VO ${ }_{2}$, peak oxygen consumption; w, week(s); y, year(s).

focused on patients who underwent roux-en-Y gastric bypass, ${ }^{1728-34}$ gastric banding, ${ }^{29} 3132$ sleeve gastric ${ }^{172931}$ or lap band ${ }^{31}$ bariatric surgery. The included studies reported data on 347 patients. The number of patients within each study ranged from 21 to 128, and years of follow-up varied from 0.25 to 1.5 (mean $=0.69, \mathrm{SD}=0.41$ ). Exercise training in all of the included studies were aerobic exercise, resistance training or combined exercise and were performed for 1.3-4hours/week and lasted for 12-26 weeks. The main characteristics of the included studies are shown in table 1 .

\section{Study quality (risk of bias)}

The quality of randomisation was considered adequate in seven studies. ${ }^{1728-313334}$ Information about random allocation concealment was provided in six studies. ${ }^{28-31} 3334$ Only two studies ${ }^{30} 34$ used a double-blind method and three studies ${ }^{17} 2833 \quad 34$ adopted a single-blind method without describing the blinding methods for outcome assessment. All included trials described the reasons for patients lost-to-follow-up in detail, with no selectivity of outcome reporting (table 2 ).

\section{Primary outcomes}

Body weight

All eight of the included studies reported changes in body weight after the intervention. Individuals assigned to an exercise training group achieved significantly greater weight loss than did those given no special exercise therapy after bariatric surgery (WMD $-1.94 \mathrm{~kg} ; 95 \%$ CI (CI) -3.18 to $-0.69 ; \mathrm{p}=0.002)$. Heterogeneity among studies was moderate $\left(\mathrm{I}^{2}=51 \%\right)$.

The subgroup analysis based on the starting time of exercise training showed that, compared with patients 
Table 2 Quality of included studies according to the Cochrane Collaboration's tool for assessment of risk of bias

\begin{tabular}{|c|c|c|c|c|c|c|c|}
\hline Study & (1) & (2) & (3) & (4) & (5) & (6) & (7) \\
\hline Coen et $\mathrm{al}^{28}$ & Low risk & Low risk & Low risk & Not clear & Low risk & Low risk & Low risk \\
\hline Herring et $a l^{29}$ & Low risk & Low risk & High risk & High risk & Low risk & Low risk & Low risk \\
\hline Hassannejad et a $\left.\right|^{17}$ & Low risk & Not clear & Low risk & Not clear & Low risk & Low risk & Low risk \\
\hline Coleman et $\left.a\right|^{31}$ & Low risk & Low risk & Not clear & Not clear & Low risk & Low risk & Low risk \\
\hline Mundbjerg et $a /^{34}$ & Low risk & Low risk & Low risk & Not clear & Low risk & Low risk & Low risk \\
\hline
\end{tabular}

(1), random-sequence generation; (2), allocation concealment; (3), blinding of participants and personnel; (4), blinding of outcome assessment;

(5), incomplete outcome data; (6), selective reporting; (7), other bias.

who began to do physical exercise within 1 year after surgery (WMD $-1.71 \mathrm{~kg} ; 95 \% \mathrm{CI}-3.06$ to -0.36 ; $\mathrm{p}=0.01$ ), those engaging in physical exercise 1 year or more after surgery achieved greater weight loss (WMD $-3.63 \mathrm{~kg}$; $95 \%$ CI -5.35 to $-1.91 ; \mathrm{p}<0.0001$; figure 2 ). The difference between groups is statistically significant $(p=0.015)$. In addition, excluding the study by Shah $e t a l^{32}$ (in which patients received the intervention at differing timepoints postsurgery), changes occurred in effect size (WMD $-2.29 \mathrm{~kg} ; 95 \% \mathrm{CI}-3.49$ to $-1.09 ; \mathrm{p}=0.0002$ ) and degree of heterogeneity $\left(\mathrm{I}^{2}=39 \%\right)$. Moreover, according to another subgroup analysis of different exercise prescriptions, the aerobic-resistance exercise group was associated with more weight loss after surgery (WMD $-3.12 \mathrm{~kg} ; 95 \%$ CI -4.56 to $-1.68 ; \mathrm{p}<0.0001$ ), while no significant difference was found in the simple aerobic-exercise group (WMD $-0.24 \mathrm{~kg} ; 95 \% \mathrm{CI}-1.56$ to $1.09 ; \mathrm{p}=0.73$ ) or the resistance exercise group (WMD $-2.20 \mathrm{~kg} ; 95 \% \mathrm{CI}-5.35$ to 0.95 ; $\mathrm{p}=0.17$; figure 3 ). The difference between groups is statistically significant $(\mathrm{p}=0.010)$.

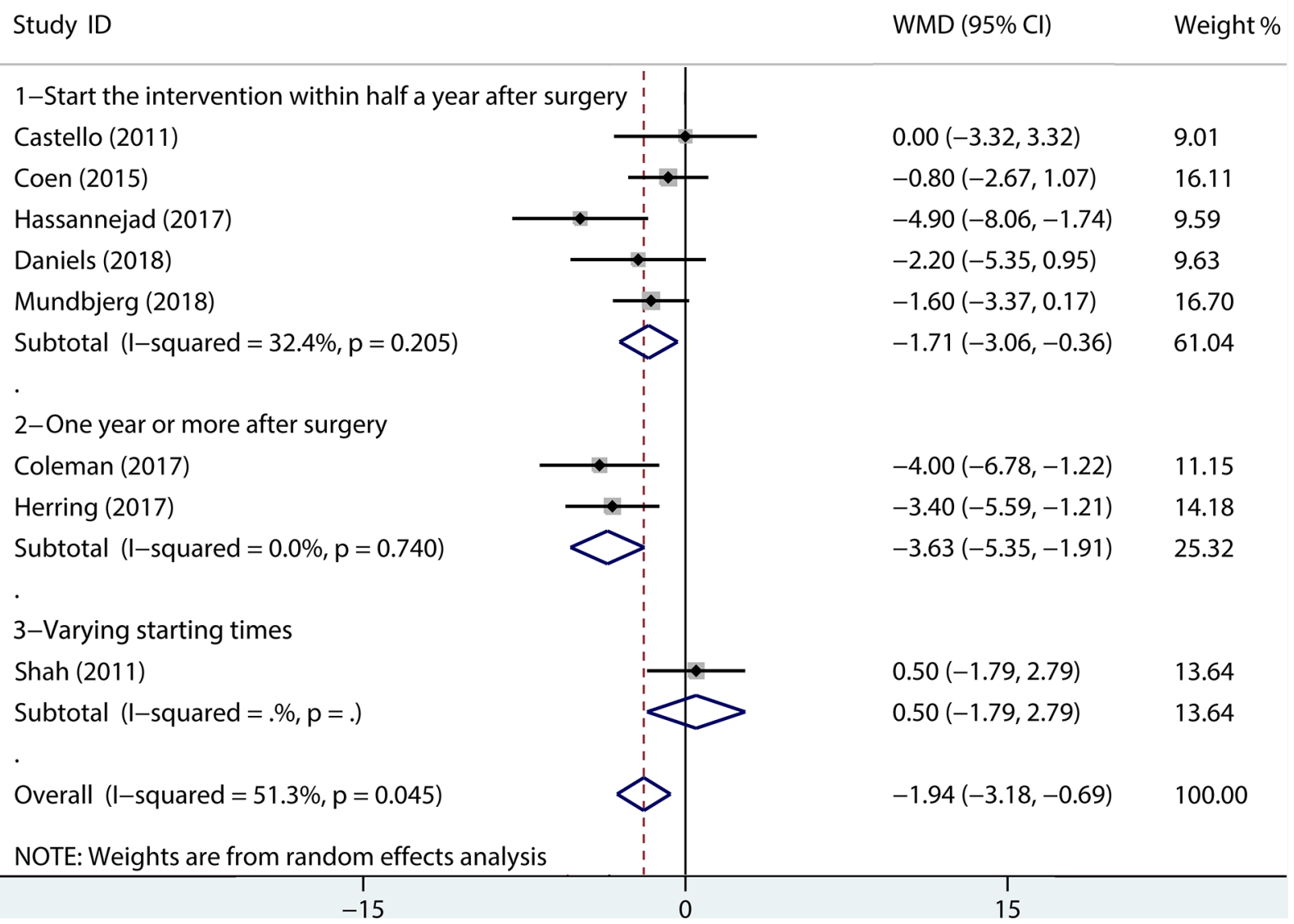

Figure 2 Mean change in body weight (kilogram) after exercise intervention versus non-exercise treatment after bariatric surgery. Subgroup analysis was done on the studies that used different starting times for intervention after surgery (Forest plot). WMD, weighted mean difference. 
Study ID

WMD $(95 \% \mathrm{Cl})$

Weight $\%$

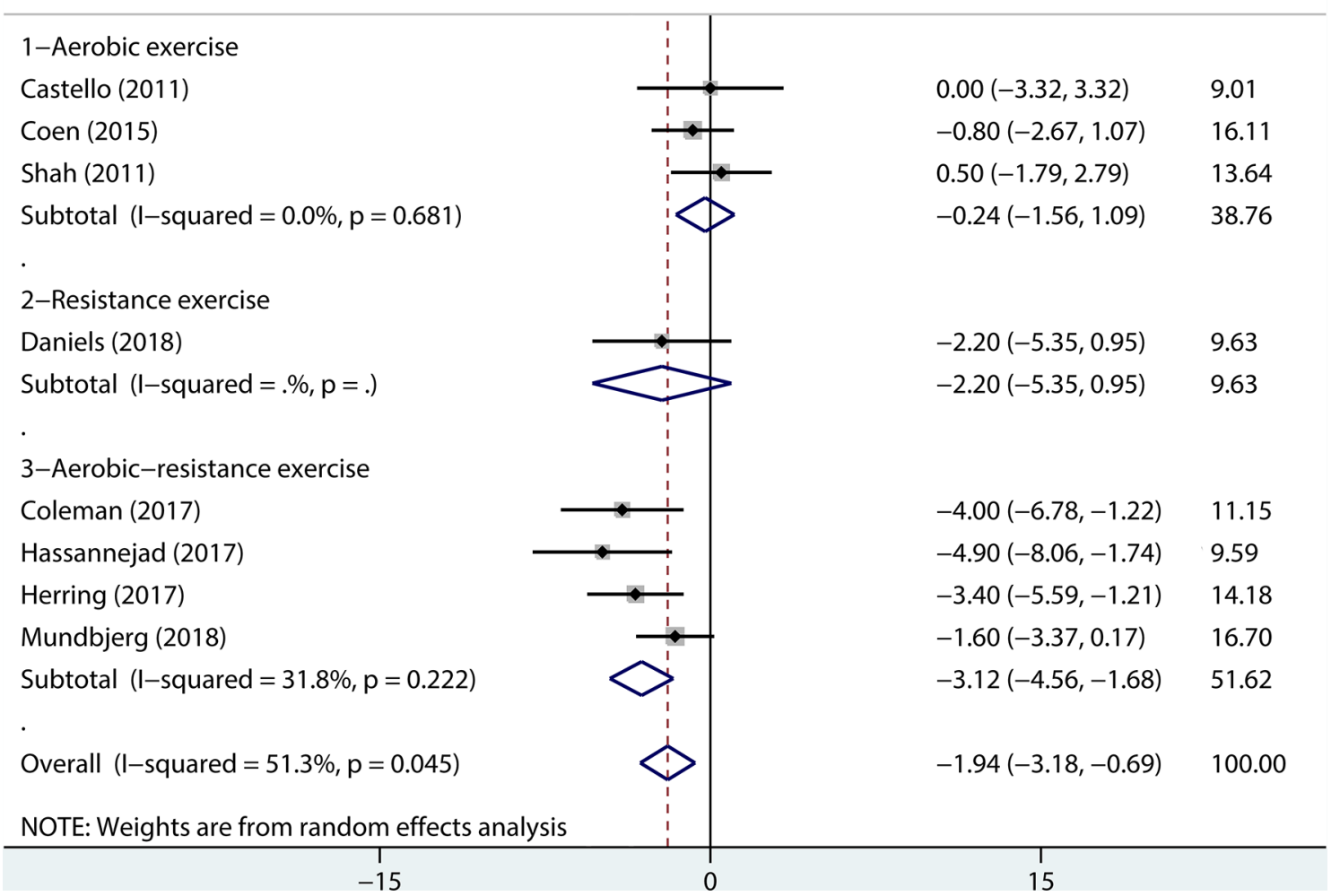

Figure 3 Mean change in body weight (kilogram) after exercise intervention versus non-exercise treatment after bariatric surgery. Subgroup analysis was done on the studies that used different exercise prescriptions after surgery (Forest plot). WMD, weighted mean difference.

\section{Physical function}

Meta-analysis based on two RCTs ${ }^{30} 31$ showed a significant increase in $6 \mathrm{~min}$ walk distance (6MWD) after the exercise intervention (6MWD; WMD $29.67 \mathrm{~m}$; 95\% CI 25.97 to $33.37 ; \mathrm{p}<0.00001)$, with good homogeneity $\left(\mathrm{I}^{2}=0 \%\right.$; online supplementary figure 1).

\section{Other outcomes}

Compared with those who did not exercise after surgery, patients receiving the exercise intervention achieved lower BMI (WMD $-0.40 \mathrm{~kg} / \mathrm{m}^{2} ; 95 \% \mathrm{CI}-0.81$ to 0.00 ; $\mathrm{n}=5$ ), smaller waist circumference (WMD $-5.25 \mathrm{~cm}$; $95 \%$ CI -10.48 to $-0.03 ; \mathrm{n}=4$ ), lower SBP (WMD $-4.12 \mathrm{~mm}$ $\mathrm{Hg} ; 95 \% \mathrm{CI}-6.68$ to $-1.55 ; \mathrm{n}=4)$ and lower resting HR (WMD $-4.39 \mathrm{bpm} ; 95 \%$ CI -8.11 to $-0.68 ; \mathrm{n}=3$ ). There was no significant difference in $\mathrm{BF} \%$ (WMD $-1.93 \%$; $95 \%$ CI -4.06 to $0.20 ; \mathrm{n}=4$ ), FM (WMD $-3.35 \mathrm{~kg} ; 95 \%$ CI -7.99 to 1.29 ; $\mathrm{n}=3$ ), FFM (WMD $0.53 \mathrm{~kg}$; $95 \%$ CI -1.88 to 2.94; $\mathrm{n}=2$ ), hip circumference (WMD $-3.91 \mathrm{~cm} ; 95 \% \mathrm{CI}$ -11.09 to $3.26 ; \mathrm{n}=3$ ) or DBP (WMD $-3.56 \mathrm{~mm} \mathrm{Hg}$; $95 \% \mathrm{CI}$ -8.61 to $1.48 ; n=4)$ between the two groups. These findings are summarised in online supplementary table 6 .

\section{Sensitivity analyses and publication bias}

Excluding studies one by one did not significantly alter the effect of exercise intervention on mean changes in body weight. Similarly, the outcome of 6MWD was not sensitive to a specific study. The funnel plot did not suggest publication bias for physical exercise with respect to weight loss (figure 4), and the $\mathrm{p}$ value for publication bias was 0.44 for the relationship between exercise training and weight loss.

\section{Overall quality of evidence by GRADEpro}

The quality of evidence for body weight and BMI were moderate. And the quality of evidence for other outcomes was downgraded to 'low' or 'very low', mainly due to high risk of performance bias, inconsistency (with a large $\mathrm{I}^{2}$

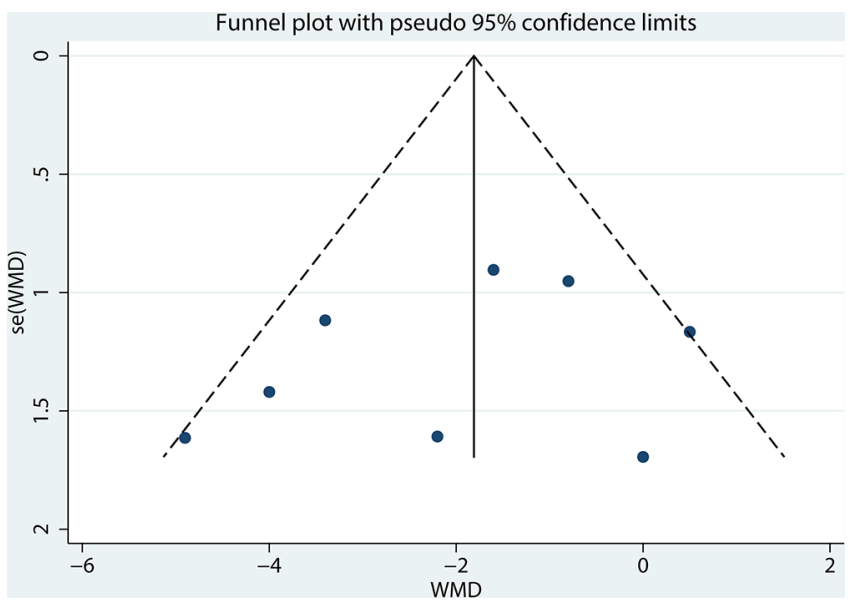

Figure 4 Weight loss: funnel plot of included studies. WMD, weighted mean difference. 
value or a wide $95 \% \mathrm{CI}$ around the pooled effect) and imprecision (small sample size). The overall results from the GRADEpro incorporating the assessment of quality of evidence for each outcome are presented in online supplementary table 7 .

\section{DISCUSSION}

To our knowledge, this is the first meta-analysis of RCTs to examine the effect of exercise on adults with obesity who have had bariatric surgery. Our results suggest that exercise following bariatric surgery elicits additional weight loss and further improves physical function.

An extra mean value of $1.94 \mathrm{~kg}$ weight loss was obtained by physical exercise after surgery, compared with surgery alone. This value is higher than $1.5 \mathrm{~kg}$, which is found in a similar meta-analysis of non-surgical weight loss programmes $^{35}$; the result is consistent with several systematic reviews ${ }^{12} 1319$ and studies based on patient self-report after bariatric surgery. ${ }^{12} 133637$ Livhits $e t$ al ${ }^{13}$ found that a $4 \%$ excess-weight loss was related to physical exercise after bariatric surgery; Pouwels et $a l^{19}$ indicated that exercise training indeed resulted in significant changes of anthropometric parameters and greater weight loss than did bariatric surgery alone. The contemporary guidelines define $5 \%$ to $10 \%$ weight reductions as clinically important to improve health. ${ }^{38} 39$ For most severe obese patients, a $20 \%$ weight loss over 2 years is required to achieve a clinical importance of health-related quality of life improvements. ${ }^{40}$ However, the current literatures have not quantified the extent to which changes in body weight are sufficient to improve health in the context of bariatric surgery. Insufficient evidence is available to conclude whether $1.94 \mathrm{~kg}$ additional weight loss is large enough to have an impact on health. Therefore, a value regarding the minimum amount of weight loss to obtain minimal clinically important difference (MCID) related to health in bariatric surgery patients need to be determined by future studies. Nevertheless, the positive results of our meta-analysis of all of the currently available RCTs indicate the causal relationship between physical activity and weight loss, proving that physical exercise contributes to more weight loss after bariatric surgery and suggesting that it can be an adjunct therapy for bariatric surgery patients, especially in cases of suboptimal weight loss.

Another systematic review focusing on physical activity and bariatric surgery with long-term follow-up (>1 year) showed a reduction of $3.62 \mathrm{~kg}$ related to physical exercise, ${ }^{12}$ which is similar to the value found by our subgroup analysis of patients engaging in exercise training $\geq 1$ year postsurgery. The studies in our subgroup analysis also indicated that weight loss was less in individuals who engaged in physical exercise at earlier periods postsurgery compared with those participated in exercise training $\geq 1$ year after surgery. This finding is consistent with two previous non-RCTs. ${ }^{18}{ }^{41}$ The strong influence of surgery ${ }^{3}$ and forced dietary changes ${ }^{42}$ are the primary factors that affect weight or fat loss at the early stages after surgery, which may weaken the desirable results of exercise training in the intervention studies. After patients have adapted to the physiological changes associated with bariatric surgery, behavioural changes begin to emerge and influence weight loss at later periods after surgery. ${ }^{43}$

In addition, different physical exercise interventions in the included studies obtained different degrees of postoperative weight reduction. According to our subgroup analysis, aerobic-resistance exercise showed obvious advantages in achieving additional weight loss compared with aerobic exercise or resistance exercise alone, which indicated that physical exercise methods might also be an important factor during exercise training after surgery. However, considering the limited sample size in the present study, further research is needed to confirm this result.

Typically, when patients undergo bariatric surgery, they lose weight rapidly in terms of both FM and FFM. ${ }^{44}$ Maximising fat loss while preserving lean-tissue mass and function is a central goal of modern obesity treatments. ${ }^{45}$ Considering that FFM accounts for a major portion of resting energy expenditure and regulation of core body temperature, its loss may predispose a patient to weight regain in the long term. ${ }^{46}$ In our meta-analysis, we failed to find a significant difference between two groups (exercise vs non-exercise) for changes in body composition (FM and FFM). On the one hand, the number of pooled studies was small and the results may have been biased; on the other hand, the results might be explained by the subjects' unclear intake of total calories and protein. According to clinical practice guidelines, ${ }^{47}$ a protein intake of roughly $1.5 \mathrm{~g} / \mathrm{kg}$ ideal body weight per day may reduce FFM loss in individuals with low energy intake. Most studies included in our meta-analysis involved diet education or provided a diet information sheet ${ }^{17} 28$ 32; however, caloric intake or protein consumption was not directly controlled or monitored, which may have affected the positive results of exercise. Different kinds of exercise regimens in the studies may be another explanation.

Physical exercise also plays a vital role in physical function. The distance travelled during the 6MWT on a horizontal surface is an easy and well-validated method for evaluating the functional abilities of obese adults. ${ }^{24} 48$ Obesity drastically inhibits physical function and walking performance and increases mobility impairments. ${ }^{49}$ Previous studies demonstrated that bariatric surgery induced substantial weight loss (especially BF\%), making walking less exhausting. ${ }^{5051}$ The present meta-analysis also showed that additional exercise training led to superior improvements in functional capacity over surgery alone, which coincided with two systematic reviews of Herring and Baillot et al. ${ }^{20} 52$ The additional mean improvements of 6MWD in the exercise training group was $29.67 \mathrm{~m}$. An MCID for the 6MWT in bariatric surgery patients has not been established. However, for patients with chronic obstructive pulmonary disease and coronary artery disease, the MCID for 6MWD is approximately $25 \mathrm{~m} .5354$ Based on this data, an additional improvement of $29.67 \mathrm{~m}$ 
observed in the exercise training group in this meta-analysis is large enough to represent a better physical function in this population. In addition, improvements shown in blood pressure and resting HR in the physical exercise group alongside increased walking distance also indicated enhanced fitness. These results suggested that aerobics and/or aerobic-resistance exercise after bariatric surgery might further increase functional capacity and resting cardiovascular fitness. However, the number of studies in this area are still limited, and most of them evaluated only postoperative functional capacity or muscle strength improvement without any physical-activity interventions. ${ }^{55} 56$ Therefore, further investigations are required to confirm the benefits of physical exercise in physical function after bariatric surgery.

The present study has several potential limitations. First, though we used a comprehensive search strategy, the quality and power of synthetic outcomes from RCTs were limited by the small sample size and small number of included studies. Second, the heterogeneity of exercise training interventions also presents challenges to evidence synthesis. Our studies indicate that exercise training, especially aerobic-resistance exercise, may augment weight loss after bariatric surgery, but we could not draw any conclusions about the frequency, duration or intensity of exercise training. Third, the results of our meta-analysis are relevant only to short-term outcomes, leading to the loss of statistical significance in some results. In future studies, we recommend that participants should be followed up for at least 2 years postsurgery to allow sufficient time for any effects of an intervention to become apparent and to determine whether physical exercise may assist postoperative weight loss maintenance.

\section{CONCLUSIONS}

Physical exercise after bariatric surgery provides additional weight loss and further improvements in physical function compared with surgery alone, which should be stressed in preoperative counselling and in long-term follow-up. However, considering the limited sample size in the present study, high-quality and larger future randomised trials are required to confirm these results and determine the best exercise prescription for adults with obesity who have had bariatric surgery.

Acknowledgements We thank Shao-Wen Tang (Department of Public Health, Nanjing Medical University) for statistical advice and L Y Herring (School of Sport, Exercise and Health Sciences, Loughborough University) for providing additional outcome data.

Contributors Z-QR was responsible for study design, literature search, data extraction and interpretation, data analysis and manuscript drafting. G-DL was responsible for literature search, data extraction and manuscript drafting. T-ZZ was responsible for data analysis, interpretation and manuscript revision. QX was responsible for study design, manuscript drafting and study supervision.

Funding The authors have not declared a specific grant for this research from any funding agency in the public, commercial or not-for-profit sectors.

Competing interests None declared.

Patient consent Not required.
Provenance and peer review Not commissioned; externally peer reviewed.

Data sharing statement № additional unpublished data are available.

Open access This is an open access article distributed in accordance with the Creative Commons Attribution Non Commercial (CC BY-NC 4.0) license, which permits others to distribute, remix, adapt, build upon this work non-commercially, and license their derivative works on different terms, provided the original work is properly cited, appropriate credit is given, any changes made indicated, and the use is non-commercial. See: http://creativecommons.org/licenses/by-nc/4.0/.

\section{REFERENCES}

1. Kissler HJ, Settmacher U. Bariatric surgery to treat obesity. Semin Nephrol 2013;33:75-89.

2. Benaiges D, Goday A, Pedro-Botet J, et al. Bariatric surgery: to whom and when? Minerva Endocrinol 2015;40:119-28.

3. Coen PM, Goodpaster BH. A role for exercise after bariatric surgery? Diabetes Obes Metab 2016;18:16-23.

4. Melton GB, Steele KE, Schweitzer MA, et al. Suboptimal weight loss after gastric bypass surgery: correlation of demographics, comorbidities, and insurance status with outcomes. J Gastrointest Surg 2008;12:250-5.

5. Pinto-Bastos A, Conceição EM, Machado PPP. Correction to: reoperative bariatric surgery: a systematic review of the reasons for surgery, medical and weight loss outcomes, and relevant behavioral factors. Obes Surg 2017;27:3069-72.

6. Jakicic JM, Davis KK. Obesity and physical activity. Psychiatr Clin North Am 2011;34:829-40.

7. Slentz CA, Houmard JA, Kraus WE. Exercise, abdominal obesity, skeletal muscle, and metabolic risk: evidence for a dose response. Obesity 2009;17 Suppl 3:S27-S33.

8. Goedecke JH, Micklesfield LK. The effect of exercise on obesity, body fat distribution and risk for type 2 diabetes. Med Sport Sci 2014;60:82-93.

9. Miller CT, Fraser SF, Levinger I, et al. The effects of exercise training in addition to energy restriction on functional capacities and body composition in obese adults during weight loss: a systematic review. PLoS One 2013;8:e81692.

10. Skrypnik D, Bogdański $P$, Mądry E, et al. Effects of endurance and endurance strength training on body composition and physical capacity in women with abdominal obesity. Obes Facts 2015;8:175-87.

11. Jakicic JM. The effect of physical activity on body weight. Obesity 2009;17 Suppl 3(n3s):S34-S38.

12. Egberts K, Brown WA, Brennan L, et al. Does exercise improve weight loss after bariatric surgery? A systematic review. Obes Surg 2012;22:335-41.

13. Livhits M, Mercado C, Yermilov I, et al. Exercise following bariatric surgery: systematic review. Obes Surg 2010;20:657-65.

14. Swartz MK. The PRISMA statement: a guideline for systematic reviews and meta-analyses. J Pediatr Health Care 2011;25:1-2.

15. Higgins JP, Altman DG, Gøtzsche PC, et al. The Cochrane Collaboration's tool for assessing risk of bias in randomised trials. BMJ 2011;343:d5928.

16. Higgins J, Green SE. The Cochrane Collaboration. Cochrane Handbook for Systematic Reviews of Interventions. Version 5.1.0[M] : Naunyn-Schmiedebergs Archiv für experimentelle Pathologie und Pharmakologie, 2011:S38.

17. Hassannejad A, Khalaj A, Mansournia MA, et al. The effect of aerobic or aerobic-strength exercise on body composition and functional capacity in patients with bmi $\geq 35$ after bariatric surgery: a randomized control trial. Obes Surg 2017;27:2792-801.

18. Huck CJ. Effects of supervised resistance training on fitness and functional strength in patients succeeding bariatric surgery. $J$ Strength Cond Res 2015;29:589-95.

19. Pouwels S, Wit M, Teijink JA, et al. Aspects of exercise before or after bariatric surgery: a systematic review. Obes Facts 2015;8:132-46.

20. Baillot A, Audet M, Baillargeon JP, et al. Impact of physical activity and fitness in class II and III obese individuals: a systematic review. Obes Rev 2014;15:721-39.

21. Bueno NB, de Melo IS, de Oliveira SL, et al. Very-low-carbohydrate ketogenic diet v. low-fat diet for long-term weight loss: a metaanalysis of randomised controlled trials. Br J Nutr 2013;110:1178-87.

22. Courcoulas AP, Christian NJ, Belle SH, et al. Longitudinal Assessment of Bariatric Surgery (LABS) Consortium. Weight change and health outcomes at 3 years after bariatric surgery among individuals with severe obesity. JAMA 2013;310:2416-25.

23. Maniscalco M, Zedda A, Giardiello $C$, et al. Effect of bariatric surgery on the six-minute walk test in severe uncomplicated obesity. Obes Surg 2006;16:836-41. 
24. de Souza SA, Faintuch J, Fabris SM, et al. Six-minute walk test: functional capacity of severely obese before and after bariatric surgery. Surg Obes Relat Dis 2009;5:540-3.

25. Higgins JP, Thompson SG, Deeks JJ, et al. Measuring inconsistency in meta-analyses. BMJ 2003;327:557-60.

26. Borenstein M, Hedges LV, Higgins JPT, et al. Introduction to MetaAnalysis, 2009.

27. Egger M, Davey Smith G, Schneider M, et al. Bias in meta-analysis detected by a simple, graphical test. BMJ 1997;315:629-34.

28. Coen PM, Tanner CJ, Helbling NL, et al. Clinical trial demonstrates exercise following bariatric surgery improves insulin sensitivity. J Clin Invest 2015;125:248-57.

29. Herring LY, Stevinson C, Carter P, et al. The effects of supervised exercise training 12-24 months after bariatric surgery on physical function and body composition: a randomised controlled trial. Int J Obes 2017;41:909-16.

30. Castello V, Simões RP, Bassi D, et al. Impact of aerobic exercise training on heart rate variability and functional capacity in obese women after gastric bypass surgery. Obes Surg 2011;21:1739-49.

31. Coleman KJ, Caparosa SL, Nichols JF, et al. Understanding the capacity for exercise in post-bariatric patients. Obes Surg 2017;27:51-8.

32. Shah M, Snell PG, Rao S, et al. High-volume exercise program in obese bariatric surgery patients: a randomized, controlled trial. Obesity 2011;19:1826-34.

33. Daniels P, Burns RD, Brusseau TA, et al. Effect of a randomised 12-week resistance training programme on muscular strength, cross-sectional area and muscle quality in women having undergone Roux-en-Y gastric bypass. J Sports Sci 2018;36:529-35.

34. Mundbjerg LH, Stolberg CR, Cecere S, et al. Supervised physical training improves weight loss after roux-en-y gastric bypass surgery: A randomized controlled trial. Obesity 2018;26:828-37.

35. Shaw K, Gennat H, O'Rourke P, et al. Exercise for overweight or obesity. Cochrane Database Syst Rev 2006:CD003817.

36. Welch G, Wesolowski C, Zagarins S, et al. Evaluation of clinical outcomes for gastric bypass surgery: results from a comprehensive follow-up study. Obes Surg 2011;21:18-28.

37. Bond DS, Phelan S, Wolfe LG, et al. Becoming physically active after bariatric surgery is associated with improved weight loss and healthrelated quality of life. Obesity 2009;17:78-83.

38. Centre for Public Health Excellence at NICE (UK); National Collaborating Centre for Primary Care (UK). Obesity: The Prevention, Identification, Assessment and Management of Overweight and Obesity in Adults and Children. 2006;10:117-23.

39. Jensen MD, Ryan DH, Apovian CM, et al. 2013 AHA/ACC/TOS guideline for the management of overweight and obesity in adults: a report of the American College of Cardiology/American Heart Association Task Force on Practice Guidelines and The Obesity Society. J Am Coll Cardiol 2014;63:2985-3023.

40. Warkentin LM, Majumdar SR, Johnson JA, et al. Weight loss required by the severely obese to achieve clinically important differences in health-related quality of life: two-year prospective cohort study. BMC Med 2014;12:1-9.
41. Stegen S, Derave W, Calders P, et al. Physical fitness in morbidly obese patients: effect of gastric bypass surgery and exercise training. Obes Surg 2011;21:61-70.

42. Sarwer DB, Dilks RJ, West-Smith L. Dietary intake and eating behavior after bariatric surgery: threats to weight loss maintenance and strategies for success. Surg Obes Relat Dis 2011;7:644-51.

43. Kalarchian MA, Marcus MD, Courcoulas AP, et al. Optimizing longterm weight control after bariatric surgery: a pilot study. Surg Obes Relat Dis 2012;8:710-5.

44. Chaston TB, Dixon JB, O'Brien PE. Changes in fat-free mass during significant weight loss: a systematic review. Int $J$ Obes 2007;31:743-50.

45. Heymsfield SB, Gonzalez MC, Shen W, et al. Weight loss composition is one-fourth fat-free mass: a critical review and critique of this widely cited rule. Obes Rev 2014;15:310-21.

46. Müller MJ, Bosy-Westphal A, Kutzner D, et al. Metabolically active components of fat-free mass and resting energy expenditure in humans: recent lessons from imaging technologies. Obes Rev 2002;3:113-22

47. Mechanick JI, Youdim A, Jones DB, et al. Clinical practice guidelines for the perioperative nutritional, metabolic, and nonsurgical support of the bariatric surgery patient--2013 update: cosponsored by American Association of Clinical Endocrinologists, the Obesity Society, and American Society for Metabolic \& Bariatric Surgery. Surg Obes Relat Dis 2013;9:159-91.

48. ATS statement. guidelines for the six-minute walk test. Am J Respir Crit Care Med 2002;166:111-7.

49. Miller GD, Nicklas BJ, You T, et al. Physical function improvements after laparoscopic Roux-en-Y gastric bypass surgery. Surg Obes Relat Dis 2009;5:530-7.

50. Vargas CB, Picolli F, Dani C, et al. Functioning of obese individuals in pre- and postoperative periods of bariatric surgery. Obes Surg 2013;23:1590-5.

51. da Silva RP, Martinez D, Faria CC, et al. Improvement of exercise capacity and peripheral metaboreflex after bariatric surgery. Obes Surg 2013;23:1835-41.

52. Herring LY, Stevinson C, Davies MJ, et al. Changes in physical activity behaviour and physical function after bariatric surgery: a systematic review and meta-analysis. Obes Rev 2016;17:250-61.

53. Holland AE, Hill CJ, Rasekaba T, et al. Updating the minimal important difference for six-minute walk distance in patients with chronic obstructive pulmonary disease. Arch Phys Med Rehabil 2010;91:221-5.

54. Gremeaux V, Troisgros $\mathrm{O}$, Benaïm S, et al. Determining the minimal clinically important difference for the six-minute walk test and the 200-meter fast-walk test during cardiac rehabilitation program in coronary artery disease patients after acute coronary syndrome. Arch Phys Med Rehabil 2011;92:611-9.

55. de Souza SA, Faintuch J, Sant'anna AF. Effect of weight loss on aerobic capacity in patients with severe obesity before and after bariatric surgery. Obes Surg 2010;20:871-5.

56. Josbeno DA, Jakicic JM, Hergenroeder A, et al. Physical activity and physical function changes in obese individuals after gastric bypass surgery. Surgery for Obesity and Related Diseases 2010;6:361-6. 